\title{
Article \\ A Model Tree-Based Vehicle Emission Model at Freeway Toll Plazas
}

\author{
Yueru Xu ${ }^{1,2,3, *}$, Chao Wang ${ }^{1,2,3}$, , Yuan Zheng ${ }^{3,4}$, Zhuoqun Sun ${ }^{1,2,3}$ and Zhirui Ye ${ }^{1,2,3}$ \\ 1 Jiangsu Key Laboratory of Urban ITS, Southeast University, Nanjing 210096, China; \\ wangchao1990@seu.edu.cn (C.W.); sunzhuoqun@seu.edu.cn (Z.S.); yezhirui@seu.edu.cn (Z.Y.) \\ 2 Jiangsu Province Collaborative Innovation Center of Modern Urban Traffic Technologies, \\ Nanjing 210096, China \\ 3 School of Transportation, Southeast University, Nanjing 210096, China; SeuZhengY@163.com \\ 4 Department of Logistics \& Maritime Studies, The Hong Kong Polytechnic University, Hong Kong, China \\ * Correspondence: xuyr1992@163.com
}

Received: 9 October 2020; Accepted: 27 October 2020; Published: 28 October 2020

check for updates

\begin{abstract}
With the increased concern over sustainable development, many efforts have been made to alleviate air quality deterioration. Freeway toll plazas can cause serious pollution, due to the increased emissions caused by stop-and-go operations. Different toll collections and different fuel types obviously influence the vehicle emissions at freeway toll plazas. Therefore, this paper proposes a model tree-based vehicle emission model by considering these factors. On-road emissions data and vehicle operation data were obtained from two different freeway toll plazas. The statistical analysis indicates that different methods of toll collection and fuel types have significant impacts on vehicle emissions at freeway toll plazas. The performance of the proposed model was compared with a polynomial regression method. Based on the results, the mean absolute percentage error (MAPE), root mean squared error (RMSE), and mean absolute error (MAE) of the proposed model were all smaller, while the $R$-squared value increased from 0.714 to 0.833 . Finally, the variations of vehicle emissions at different locations of freeway toll plazas were calculated and shown in heat maps. The results of this study can help better estimate the vehicle emissions and give advice to the development of electronic toll collection (ETC) lanes and relevant policies at freeway toll plazas.
\end{abstract}

Keywords: vehicle emissions; freeway toll plaza; vehicle specific power; model tree

\section{Introduction}

With the degradation of the environment, sustainable development has drawn wide attention around the world [1-3]. Various studies have investigated the air pollution caused by transportation systems [4-6]. Lumbreras et al. [7] argue that vehicle emissions in transportation networks are a major cause of air pollutants, including $\mathrm{NO}_{\mathrm{x}}, \mathrm{CO}, \mathrm{PM} 2.5, \mathrm{HC}$, and $\mathrm{CO}_{2}$. Vehicle emissions during travel on freeways can influence air quality from two aspects. One is the direct emission of pollutants; another is the chemical reaction of emitted pollutants [8,9]. Toll plazas are an essential part of freeway operations and management. Vehicles spend a certain period passing through the toll plaza, which includes the process of decelerating to the toll plaza, paying the toll, and then accelerating back to running speed [10]. In particular, vehicles at freeway toll plazas can emit more emissions and generate more air pollution due to the stop-and-go or slow-and-go behaviors of vehicles [11-13]. Therefore, an increasing number of studies pay attention to the urgent problem of vehicle emissions at freeway toll plazas [14].

Estimating emissions at freeway toll plazas is a complex effort in China, as it requires the consideration of the freeway toll collection methods. Currently, the two main freeway toll collection methods in China are manual toll collection (MTC) and electronic toll collection (ETC). 
Conventional MTC requires vehicles to stop completely to pay the toll. One strong impact of this type of toll collection is that the emissions of vehicles will increase because of the excessive delays, long queues, and speed variation cycles for approaching vehicles [15]. As one of the most widespread technologies of intelligent transportation systems (ITSs), ETC enables drivers to pay by only slowing down instead of a complete stop [16]. ETC not only contributes to the reduced congestion in toll plazas, but also has been proven in previous studies as an promising approach that contributes to reduced fuel consumption and vehicle emissions compared to MTC, due to the mitigation of congestion and stop-and-go operations [17]. In addition, ETC enables freeway management agencies to collect freeway traffic data, including the number and type of vehicles, travel route, time and speed, and vehicle numbers equipped with the ETC transponders [9].

\subsection{Literature Review}

With the increasing number of studies relating to vehicle emission estimation, the research methods in mainstream references are classified into two main categories [18]. The first category is carried out by driving the vehicle through planned driving cycles on chassis dynamometers in laboratories. For instance, Saka and Agboh [17] conducted a study to analyze the effects of ETC on reducing air pollution by applying both deterministic and simulation models at three major toll plazas. However, the test conditions in laboratories are limited, and cannot represent all naturalistic on-road driving conditions [19-21]. The second category is conducted by measuring vehicle emissions directly from the tailpipe of testing vehicles under naturalistic driving conditions, which is more effective and popular than the first category [22-24].

Regression models are most commonly used in vehicle emission estimation and prediction studies, due to their superior performance and ability to integrate with the Geographic Information System (GIS). A Virginia Tech microscopic energy and emission model was developed by Rakha et al., based on numerous polynomial combinations of speed and acceleration levels to evaluate vehicle emissions [25]. The model was validated by comparing against laboratory measurements with prediction errors within $17 \%$. Ruths et al. [26] proposed a spatio-temporal model based on a multiple regression algorithm to evaluate the ultrafine particles and black carbon (BC) concentrations from vehicle emissions. The model shows a good performance based on the results.

With the development of computer science, machine learning methods are becoming popular in various aspects, including vehicle emission estimation, due to its outstanding performance and fewer restrictions [27,28]. Wang et al. [29] developed a vehicle-specific power (VSP)-based artificial neural network (ANN) model to predict the emissions of urban buses. The results indicate that it can improve $R$-squared from 0.659 to 0.781 compared to traditional polynomial regression model. Azeez et al. [30] proposed a hybrid model based on correlation-based feature selection, support vector regression, and GIS. The model achieved a validation accuracy of $80.6 \%$ for traffic $\mathrm{CO}$ assessment on roads.

To assess the performance of ETC lanes on reducing fuel consumption and vehicle emissions compared to MTC lanes, Weng et al. [31] developed a model, and discovered that ETC systems can reduce fuel consumption for about 4.1 million liters and mitigate air pollution for approximately 730.89 tons per year in Beijing. An experiment in Thailand investigated the impact of ETC systems on energy saving and $\mathrm{CO}_{2}$ emission [32]. They argued that using an ETC system can significantly reduce fuel consumption and vehicle emissions compared to MTC. Bari et al. [33] quantified the characteristics of vehicle emissions at freeway toll plazas in complex traffic situations. The conclusions show that the vehicles produce more emissions during idling conditions while waiting and during the transaction. The application of the ETC system can reduce the idling cycle situation, thus reduce vehicle emissions.

\subsection{Objective of the Paper}

Although previous studies have discovered the characteristics of vehicle emissions under different conditions at freeway toll plazas, some limitations still exist and need to be further explored. The limitations of previous studies can be concluded in three main aspects: (a) though various 
machine learning methods have been applied on vehicle emission estimation, few model tree-based approaches have been used in estimating vehicle emissions at freeway toll plazas; (b) the existing studies only pay attention to the certain type of vehicles for their emission performance, and few studies focus on the comparison of vehicle emissions for different fuel types of vehicles; (c) previous studies seldom explore vehicle emissions and their variation at different locations of freeway toll plazas. Therefore, an exhaustive study should be conducted in order to model and estimate vehicle emissions for freeway toll plazas, and explore the difference in vehicle emissions between ETC and MTC.

Given the above-mentioned knowledge gaps, a model tree-based study was conducted to model and estimate vehicle emissions for different fuel types at freeway toll plazas, and explore the difference in vehicle emissions between ETC and MTC. The objectives of this paper are mainly encompassed by three aspects: (a) estimate and predict vehicle emissions at freeway plazas more accurately, (b) holistically consider the emissions from multiple fuel types of vehicles, and (c) map the spatial variation of vehicle emissions at different locations of freeway toll plazas.

The remaining sections of the paper are organized as follows: Section 2 introduces the proposed model to estimate vehicle emissions at freeway toll plazas. Section 3 presents the results and relevant discussion. Section 4 concludes the findings of the paper.

\section{Methods}

In order to compare the differences in vehicle speed, acceleration, delay time, and emissions values, and estimate the vehicle emissions at freeway toll plazas for petrol and diesel vehicles, the following methods were applied. (1) Differences in vehicle operations and emissions-statistical methods were used to analyze the collected data, in order to explore the differences between ETC and MTC for petrol and diesel vehicles, respectively. (2) Calculation formula of vehicle specific power (VSP), which is regarded as an surrogate parameter relating to vehicle transient speed, acceleration, total mass, and road grade; this parameter can reflect the situation of vehicle emissions [34]. Various studies have applied VSP to estimate vehicle emissions, due to its direct physical interpretation and strong statistical correlation [35]. (3) Lastly, vehicle emission estimation using model trees: a model tree-based method is proposed in this section. It is an extension of regression trees that generate binary decision trees [36]. The overall process of the methodology is listed in Figure 1.

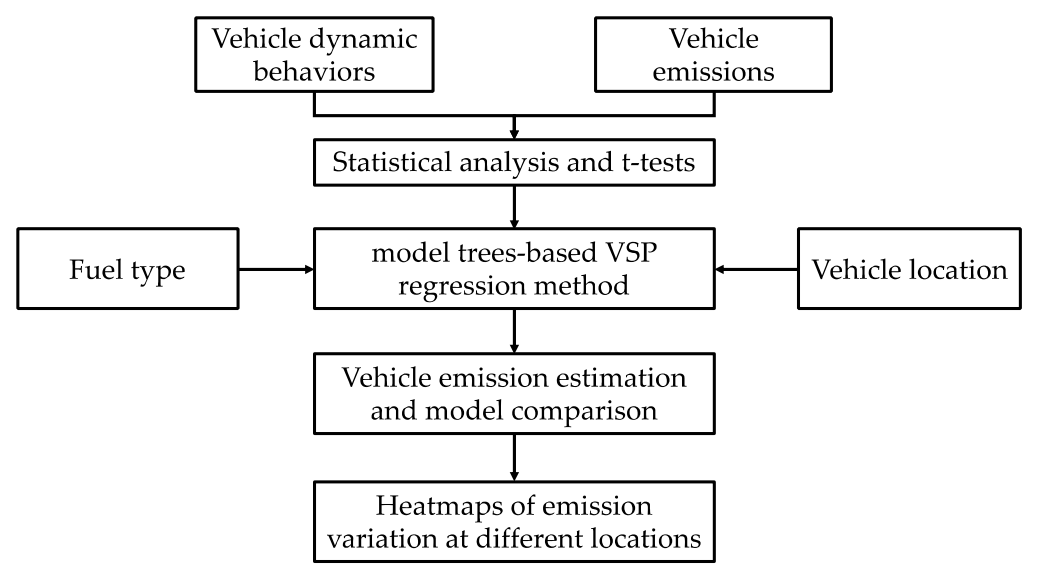

Figure 1. Overall methodology process.

\subsection{Data Collection}

The measurements of traffic parameters in this study were collected at two toll plazas, including Qixia toll plaza (located on freeway G42, which connects the cities of Shanghai and Chengdu) and Zhenjiang toll plaza (located on freeway 2501, which connects the cities of Nanjing and Shanghai). Both of the plazas are consists of eight toll booths, including two booths operate in ETC mode. 
The speed limit of ETC lanes is $60 \mathrm{~km} / \mathrm{h}$. The data were collected during September 25 and 28, 2016 . The collection process was conducted during sunny weather to exclude the impact of bad weather.

The second-by-second gaseous exhaust emissions were collected and recorded by an AUTOplus automotive gas emission analyzer unit. The product can measure air pollutants like $\mathrm{CO}, \mathrm{HC}, \mathrm{O}_{2}, \mathrm{CO}_{2}$, and $\mathrm{NO}_{\mathrm{X}}$ and is proper for vehicle emission measurement. According to previous research [37], PM2.5 from vehicle emission is not the main source of PM2.5 in urban areas. The PM2.5 in urban areas caused by traffic emission only accounts for less than $3 \%$. Therefore, PM2.5 is not considered in this study. A probe was inserted into the tailpipe of the testing vehicles, and connected with the device by a flexible hose line. A petrol passenger car (petrol vehicle) and a diesel-fueled passenger bus (diesel vehicle) were selected in this study to collect vehicle emission. Moreover, the second-by-second GPS data were collected by a global positioning system receiver model GPS 16-HVS in order to obtain vehicle speed, acceleration, and delay time. Before each individual test, standard calibration gases were used to verify and calibrate the system, and target pollutants were set to zero [38].

\subsection{Calculation Formula of VSP}

Vehicle-specific power (VSP) was applied in this study to calculate the fuel consumption. This parameter is defined as the instantaneous power per unit mass of the vehicle. It is an estimation of the power demand on the engine during driving, and was first proposed by Jimenez-Palacios [39]. It can be calculated by multiplying speed by equivalent acceleration. The expression of VSP can be written as:

$$
\begin{gathered}
V S P=\frac{P o w e r}{M a s s}=\frac{F_{t} v}{m}=\frac{\left(G \sin \alpha+F_{w}+F_{a}+F_{f}\right) \cdot v}{m} \\
=\frac{\left[m g \sin \alpha+0.5 \rho_{a} C_{d} A \cdot\left(v+v_{w w}\right)^{2}+(1+\varepsilon) \cdot m a+\mu m g \cos \alpha\right] \cdot v}{m} \\
=[g \sin \alpha+(1+\varepsilon) \cdot a+\mu g \cos \alpha] \cdot v+\frac{0.5 \rho_{a} C_{d} A \cdot\left(v+v_{w}\right)^{2} \cdot v}{m}
\end{gathered}
$$

where $F_{t}$ means the vehicle traction $(\mathrm{N}) ; v$ means the transient speed $(\mathrm{m} / \mathrm{s}) ; m$ is the total vehicle mass $(\mathrm{kg}) ; G$ means gravity of the vehicle $(\mathrm{N}) ; F_{w}, F_{a}$, and $F_{f}$ mean wind resistance, acceleration resistance, and rolling resistance, respectively $(\mathrm{N}) ; g$ is the gravitational acceleration $\left(9.81 \mathrm{~m} / \mathrm{s}^{2}\right) ; \rho_{a}$ denotes the ambient air density $\left(1.207 \mathrm{~kg} / \mathrm{m}^{3}\right.$ at $\left.20^{\circ} \mathrm{C}\right) ; C_{d}$ is the drag coefficient $(0.6) ; \mu$ is the rolling resistance coefficient; $\alpha$ represents the road grade; $A$ means the frontal area of the vehicle $\left(\mathrm{m}^{2}\right) ; v_{w}$ represents the headwind speed into the vehicle $(\mathrm{m} / \mathrm{s}) ; \varepsilon$ represents the mass factor; and $a$ represents the vehicle acceleration value $\left(\mathrm{m} / \mathrm{s}^{2}\right)$.

Based on Equation (1), VSP is a direct measure of engine load on a vehicle, which characterizes vehicle and driving profiles using real-word, on-road data, including the transient speed, vehicle total mass, road grade, and load coefficient [40]. The rolling resistance coefficient was determined by road surface conditions and vehicle tire conditions [41]. In this research, a constant coefficient value was selected ( $\mu=0.0135$ ), according to the road surface condition of the test road and the vehicle tire type used in the test. Previous studies have estimated the typical values of $\varepsilon$ in different gears [34]. The value equals 0.25 in first gear, 0.15 in second gear, 0.10 in third gear, and 0.075 in fourth gear. We use the value 0.10 in this section for both petrol passenger cars and diesel-fueled passenger buses, since third gear is most widely applied in naturalistic driving experiments. Moreover, the road grade and headwind speed were assumed to be zero, since freeway toll plazas in this study are in flat areas and the weather was good during collection. The frontal area of the petrol passenger car and diesel-fueled passenger bus were $1.9 \mathrm{~m}^{2}$ and $8.3 \mathrm{~m}^{2}$, respectively, and the total mass of the petrol passenger car and diesel-fueled passenger bus were $1570 \mathrm{~kg}$ and $14,200 \mathrm{~kg}$, respectively.

\subsection{Vehicle Emission Estimation Using Model Trees}

Finally, we proposed a model tree-based model to estimate vehicle emissions. The advantage of this method is that the model represents simple rules and is easier to train [42]. Different from other machine learning methods, model trees are transparent and easier to understand [43]. In addition, model-tree-based models are superior for handling both linear and non-linear relationships in a 
complex dataset. In a decision tree, each internal node in the tree represents a "test" on an attribute, while the branches mean different results of the test. In addition, each leaf node is regarded as a class label.

Model trees have shown outstanding performance in addressing continuous class problems [43]. In this method, data at each leaf node are treated as a simple constant value. This process can be achieved by modeling the data as a piecewise linear model containing several linear segments at each leaf node [44]. The structure of model trees, as shown in Figure 2, is similar to the conventional decision tree. The difference is that model trees use linear models rather than discrete class labels at the leaves. M5 model trees, proposed by Quinlan [42], are effective model trees for real values. This method was then reconstructed and improved by Wang and Witten [45] to achieve better performance, which called M5' model trees. We applied M5' model trees in this paper, since this method is most widely used and the performance is superior compared to other model trees.

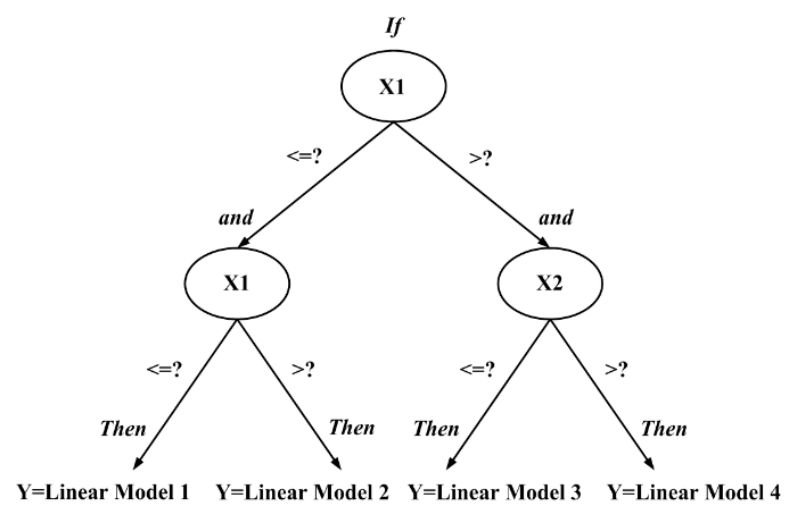

Figure 2. The skeleton of model trees.

The process of this method can be concluded as follows.

Step 1 is building the initial tree. For M5' model trees, the splitting criterion is that the measurement of the error at one node can be regarded as the standard deviation of the class values that reach the node. Then calculate the expected reduction in error, in order to represent each attribute at that node. Finally, the attribute with the largest expected error reduction will be adopted [45]. The standard deviation reduction $(S D R)$ can be expressed as follows:

$$
S D R=s d(T)-\sum_{i} \frac{\left|T_{i}\right|}{|T|} \times s d\left(T_{i}\right)
$$

where $s d$ represents the standard deviation; $T$ represents the example sets that reach the node; and $T_{i}$ represents the sets that are generated by splitting the node, based on the selected attribute.

Step 2 is pruning the tree. After building the initial tree, the value of each interior node should be calculated by a linear multiple regression model. The attributes will be dropped in sequence while the values are lower than the estimated error. According to relevant references [45], we can obtain the expected error by averaging the absolute difference between the actual and predicted values for every training example. This average, however, will result in underestimation for unseen cases. Thus, a parameter $(n+v) /(n-v)$ is multiplied by the expected error, where $n$ represents the training sample size of the node, and $v$ represents the parameter number in the model that represents the class value at that node.

Step 3 is smoothing. After the second step, the adjacent linear models will become discontinuous at the leaves, especially for those based on a limited size of training samples. Therefore, a smoothing 
process is conducted to form the final model. In this step, the estimated value of the leaf model will be filtered along the path back to the root [43]. This can be written as

$$
p^{\prime}=\frac{n p+k q}{n+k}
$$

where $p^{\prime}$ represents the predicted value passed up to the higher node; $p$ donates the predicted value passed to this node from the lower node; $q$ denotes the value predicted by the model at this node; and $k$ is a constant value. Relevant research studies have shown that the accuracy of predictions can be improved by smoothing [45].

\section{Results and Discussion}

\subsection{Data Descriptive Analysis}

Table 1 presents the dynamic behavior and emission of vehicles at freeway toll plazas. SS represents the sample size. It should be noted that toll collection merging behavior is the main cause of the delay time at freeway toll plazas. By observing the mean value and standard error of each variable in Table 1 , we can find that there are some differences between ETC and MTC lanes, as well as petrol and diesel vehicles. This indicates that different types of toll collections and different vehicle fuel types may have a significant influence on the vehicle operations and emissions at freeway toll plazas. Further statistical analysis should be conducted to explore and verify this hypothesis.

Table 1. Vehicle operations and emissions at freeway toll plazas.

\begin{tabular}{|c|c|c|c|c|c|c|c|c|}
\hline Var & ables & Fuel & Type & SS & Max & Min & Mean & SD \\
\hline \multirow{12}{*}{$\begin{array}{l}\text { Dynamic } \\
\text { vehicle } \\
\text { behaviors }\end{array}$} & \multirow{4}{*}{$\begin{array}{l}\text { Speed } \\
(\mathrm{km} / \mathrm{h})\end{array}$} & \multirow{2}{*}{ Petrol } & ETC & 1352 & 67.21 & 22.04 & 49.46 & 9.53 \\
\hline & & & MTC & 1352 & 54.05 & 0.00 & 14.38 & 12.23 \\
\hline & & \multirow{2}{*}{ Diesel } & ETC & 1352 & 58.05 & 12.75 & 31.61 & 8.65 \\
\hline & & & MTC & 1352 & 47.53 & 0.00 & 12.83 & 12.72 \\
\hline & \multirow{4}{*}{$\begin{array}{l}\text { Acceleration } \\
\qquad\left(\mathrm{m} / \mathrm{s}^{2}\right)\end{array}$} & \multirow{2}{*}{ Petrol } & ETC & 1352 & 0.67 & -0.56 & 0.02 & 0.44 \\
\hline & & & MTC & 1352 & 0.97 & -1.53 & -0.12 & 0.53 \\
\hline & & \multirow{2}{*}{ Diesel } & ETC & 1352 & 0.62 & -0.64 & -0.04 & 0.45 \\
\hline & & & MTC & 1352 & 1.05 & -0.69 & -0.01 & 0.46 \\
\hline & \multirow{4}{*}{$\begin{array}{c}\text { Delay time } \\
\text { (s) }\end{array}$} & \multirow{2}{*}{ Petrol } & ETC & 52 & 15.13 & 4.02 & 8.18 & 2.16 \\
\hline & & & MTC & 52 & 161.78 & 37.24 & 82.68 & 31.80 \\
\hline & & \multirow{2}{*}{ Diesel } & ETC & 52 & 18.95 & 7.11 & 11.19 & 3.38 \\
\hline & & & MTC & 52 & 172.89 & 35.12 & 95.59 & 38.49 \\
\hline \multirow{16}{*}{$\begin{array}{l}\text { Vehicle } \\
\text { emissions }\end{array}$} & \multirow{4}{*}{$\begin{array}{l}\mathrm{CO} \\
(\mathrm{g} / \mathrm{s})\end{array}$} & \multirow{2}{*}{ Petrol } & ETC & 1352 & $1.90 \times 10^{-2}$ & $5.81 \times 10^{-3}$ & $9.69 \times 10^{-3}$ & $3.65 \times 10^{-3}$ \\
\hline & & & MTC & 1352 & $2.10 \times 10^{-2}$ & $1.21 \times 10^{-2}$ & $1.43 \times 10^{-2}$ & $1.87 \times 10^{-3}$ \\
\hline & & \multirow{2}{*}{ Diesel } & ETC & 1352 & $1.08 \times 10^{-1}$ & $7.44 \times 10^{-3}$ & $5.69 \times 10^{-2}$ & $2.99 \times 10^{-2}$ \\
\hline & & & MTC & 1352 & $2.40 \times 10^{-1}$ & $4.27 \times 10^{-2}$ & $8.53 \times 10^{-2}$ & $4.77 \times 10^{-2}$ \\
\hline & \multirow{4}{*}{$\begin{array}{l}\mathrm{HC} \\
(\mathrm{g} / \mathrm{s})\end{array}$} & \multirow{2}{*}{ Petrol } & ETC & 1352 & $6.54 \times 10^{-5}$ & $3.50 \times 10^{-6}$ & $1.84 \times 10^{-5}$ & $1.58 \times 10^{-5}$ \\
\hline & & & MTC & 1352 & $9.75 \times 10^{-5}$ & $6.92 \times 10^{-5}$ & $7.63 \times 10^{-5}$ & $6.23 \times 10^{-6}$ \\
\hline & & \multirow{2}{*}{ Diesel } & ETC & 1352 & $8.99 \times 10^{-4}$ & $1.21 \times 10^{-4}$ & $3.71 \times 10^{-4}$ & $2.32 \times 10^{-4}$ \\
\hline & & & MTC & 1352 & $1.89 \times 10^{-3}$ & $3.58 \times 10^{-4}$ & $6.21 \times 10^{-4}$ & $3.55 \times 10^{-4}$ \\
\hline & \multirow{4}{*}{$\begin{array}{l}\mathrm{NO}_{X} \\
(\mathrm{~g} / \mathrm{s})\end{array}$} & \multirow{2}{*}{ Petrol } & ETC & 1352 & $5.22 \times 10^{-4}$ & $7.25 \times 10^{-6}$ & $1.29 \times 10^{-4}$ & $1.40 \times 10^{-4}$ \\
\hline & & & MTC & 1352 & $5.08 \times 10^{-4}$ & $3.05 \times 10^{-5}$ & $1.72 \times 10^{-4}$ & $8.18 \mathrm{E} \times 10^{-5}$ \\
\hline & & \multirow{2}{*}{ Diesel } & ETC & 1352 & $6.82 \times 10^{-2}$ & $1.72 \times 10^{-2}$ & $3.70 \times 10^{-2}$ & $1.58 \times 10^{-2}$ \\
\hline & & & MTC & 1352 & $8.43 \times 10^{-2}$ & $1.74 \times 10^{-2}$ & $3.95 \times 10^{-2}$ & $1.69 \times 10^{-2}$ \\
\hline & \multirow{4}{*}{$\begin{array}{l}\mathrm{CO}_{2} \\
(\mathrm{~g} / \mathrm{s})\end{array}$} & \multirow{2}{*}{ Petrol } & ETC & 1352 & 4.21 & 1.37 & 2.19 & 0.82 \\
\hline & & & MTC & 1352 & 3.77 & 1.21 & 2.85 & 0.70 \\
\hline & & \multirow{2}{*}{ Diesel } & ETC & 1352 & 5.16 & 1.17 & 2.36 & 0.98 \\
\hline & & & MTC & 1352 & 8.72 & 1.09 & 2.69 & 1.96 \\
\hline
\end{tabular}


According to the relevant references [46], four modes can be observed and concluded during driving: (1) idling mode (zero speed and acceleration), (2) acceleration mode (positive incremental speed changes of acceleration larger than $0.1 \mathrm{~m} / \mathrm{s}^{2}$ ), (3) cruising mode (absolute incremental speed changes of $0.1 \mathrm{~m} / \mathrm{s}^{2}$ or less), and (4) deceleration mode (negative incremental speed changes of acceleration larger than $0.1 \mathrm{~m} / \mathrm{s}^{2}$ ). Figure 3 presents two typical speed profiles of vehicles traveling through ETC and MTC systems at toll plazas with stop-and-go cycles. Each color in this figure represents one vehicle. We can observe that the numbers of stop-and-go or slow-and-go cycles of ETC lanes are much lower than those of MTC lanes. As shown in Figure 3a, ETC enables drivers to pay tolls by only slowing down and without a complete stop. Therefore, this process consists of the cruising mode, deceleration mode, acceleration mode, and cruising mode. Conventional MTC, however, requires drivers to pay rolls by a complete stop, i.e., including the cruising mode, deceleration mode, idling mode, acceleration mode, and cruising mode (Figure $3 b$ ).

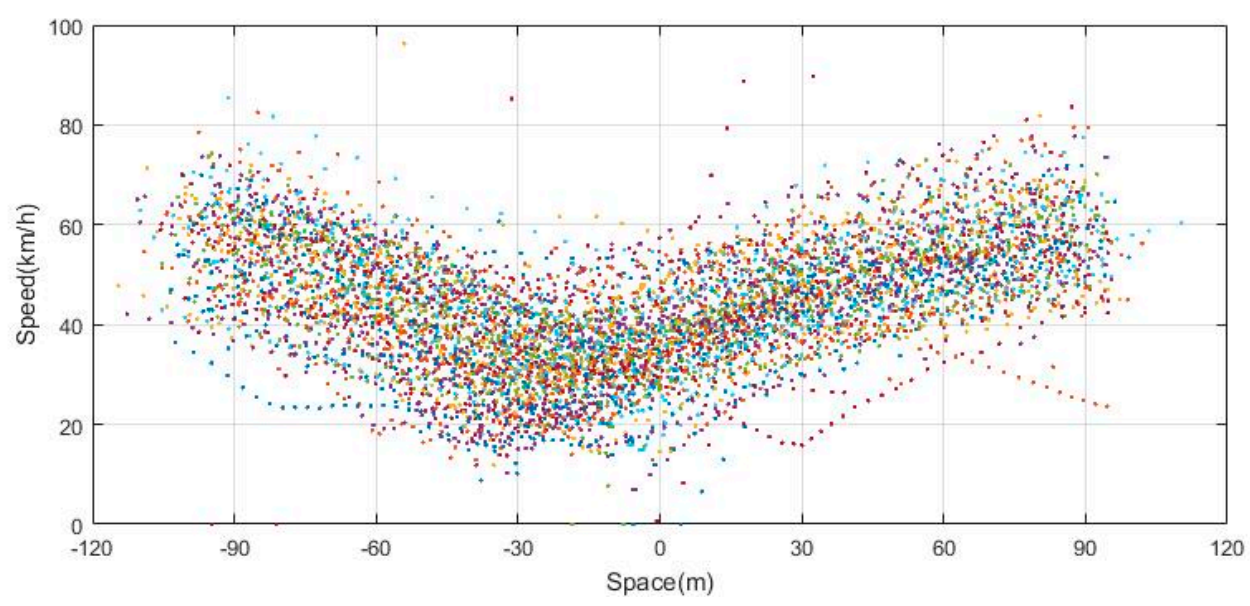

(a) Electronic toll collection (ETC)

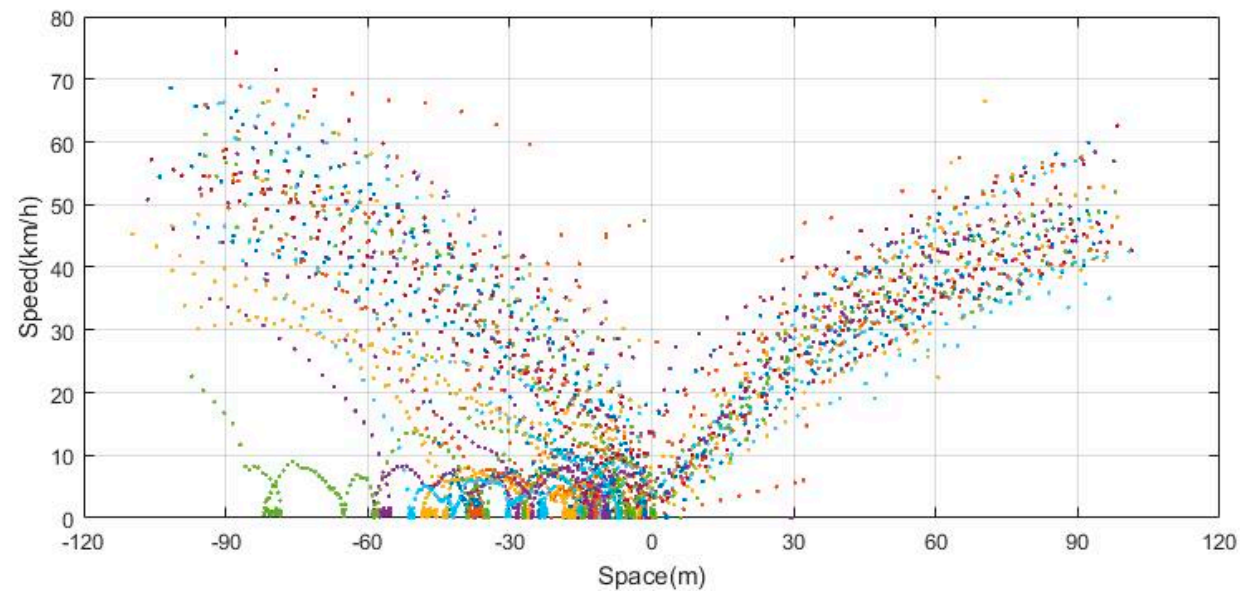

(b) Manual toll collection (MTC)

Figure 3. Typical speed profiles of vehicles traveling through ETC and MTC systems at toll plazas with stop-and-go cycles.

\subsection{Differences in Vehicle Speed, Acceleration, Delay Time, and Emissions}

Student's $t$-tests were used to explore the differences in vehicle dynamic behaviors and vehicle emissions between ETC and MTC for different fuel types of vehicles. As listed in Table 2, the results indicate that the differences in vehicle speed, acceleration, delay time, and vehicle emissions between ETC and MTC for petrol and diesel vehicles are all statistically significant. This indicates significant effects of ETC on vehicle dynamic behaviors and vehicle emissions. Estimations of vehicle emissions 
are conducted in the next section to further analyze the different performance at ETC and MTC lanes for different fuel types of vehicles.

Table 2. $p$-Values of $t$-tests for the differences in speed, acceleration, delay time, and emissions.

\begin{tabular}{cccc}
\hline \multirow{2}{*}{$t$-Test Results } & \multicolumn{2}{c}{ ETC vs. MTC } \\
\cline { 3 - 4 } & & Petrol Vehicles & Diesel Vehicles \\
\hline \multirow{2}{*}{$\begin{array}{c}\text { Dynamic vehicle } \\
\text { behaviors }\end{array}$} & Speed & $<0.001 *$ & $<0.001^{*}$ \\
& Acceleration & $0.031^{*}$ & $0.047^{*}$ \\
& Delay time & $0.007^{*}$ & $0.021^{*}$ \\
Vehicle emissions & $\mathrm{CO}$ & $0.000^{*}$ & $0.000^{*}$ \\
& $\mathrm{HC}$ & $0.000^{*}$ & $0.000^{*}$ \\
& $\mathrm{NO}_{\mathrm{X}}$ & $0.000^{*}$ & $0.000^{*}$ \\
& $\mathrm{CO}_{2}$ & $0.000^{*}$ & $0.013^{*}$ \\
\hline
\end{tabular}

* Significant at the significance level of 0.05 .

\subsection{Vehicle Emission Estimation}

By applying all the values mentioned above into Equation (1), the VSP for petrol and diesel vehicles can be written as follows:

$$
\begin{aligned}
& V S P_{\text {petrol }}=v(1.1 a+0.132)+4.38 \times 10^{-4} v^{3} \\
& V S P_{\text {diesel }}=v(1.1 a+0.132)+2.12 \times 10^{-4} v^{3}
\end{aligned}
$$

After using these formulas to calculate the VSP, we utilized the method of model tree-based VSP regression to conduct vehicle emission estimation and analysis for petrol and diesel vehicles. The 1352 samples were separated into two parts: the training set contained 1092 samples ( $80 \%$ of the samples) and was used for modeling, and the testing set included 260 samples ( $20 \%$ of the samples) for estimation and comparison. The training set was separated randomly into five equal-sized parts, and five-fold cross validation was used to evaluate the performance of the model and avoid overfitting problems. Results of the cross validation show great performance of the model. Therefore, the results of testing samples can be used for estimation and comparison.

Take emissions of CO for diesel vehicles for example - based on training data set, the M5 ${ }^{\prime}$ model tree [47] is presented in Figure 4. Based on Figure 4, there are four model tree rules: (1) if VSP $\leq-4$, then emissions of CO for diesel vehicles $=0.0170 \times \mathrm{VSP}+0.2177$; (2) If $-4<\mathrm{VSP} \leq-1$, then emissions of $\mathrm{CO}$ for diesel vehicles $=-0.0355 \times \mathrm{VSP}+0.0077$; (3) if $-1<\mathrm{VSP} \leq 2$, then emissions of CO for diesel vehicles $=0.0181 \times \mathrm{VSP}+0.0613$; and (4) if VSP $>2$, then emission sof CO for diesel vehicles $=0.0158 \times \mathrm{VSP}+0.0660$.

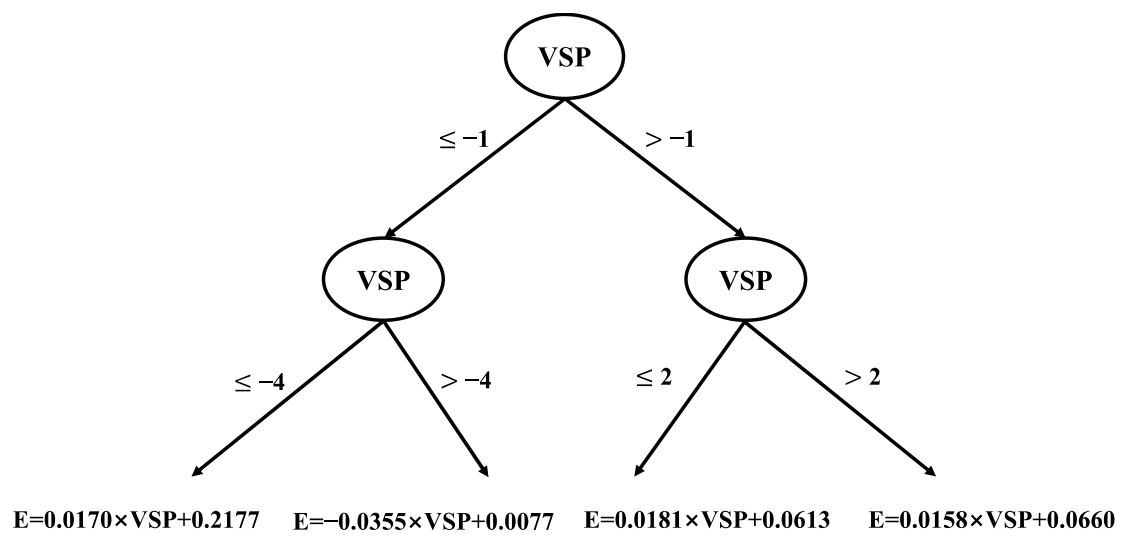

Figure 4. Model tree of emissions of $\mathrm{CO}$ for diesel vehicles. 
Thus, using the model tree method, the vehicle emissions estimation of $\mathrm{CO}, \mathrm{HC}, \mathrm{NO}_{\mathrm{X}}$, and $\mathrm{CO}_{2}$ for petrol and diesel vehicles can be expressed as follows:

(1) Vehicle emission estimation model of $\mathrm{CO}$ for diesel and petrol vehicles $(\mathrm{g} / \mathrm{s})$ :

$$
\begin{gathered}
\text { Emission }_{\text {diesel }}^{C O}=\left\{\begin{array}{lc}
0.0170 \times V S P+0.2177, & V S P \leq-4 \\
-0.0355 \times V S P+0.0077, & -4<V S P \leq-1 \\
0.0181 \times V S P+0.0613, & -1<V S P \leq 2 \\
0.0158 \times V S P+0.0660, & V S P>2
\end{array}\right. \\
\text { Emission }_{\text {petrol }}^{C O}=\left\{\begin{array}{lc}
0.0012 \times V S P+0.0233, & V S P \leq-5 \\
-0.0035 \times V S P-0.0002, & -5<V S P \leq-2 \\
0.0013 \times V S P+0.0093, & -2<V S P \leq 2 \\
0.0007 \times V S P+0.0103, & V S P>2
\end{array}\right.
\end{gathered}
$$

(2) Vehicle emission estimation model of $\mathrm{HC}$ for diesel and petrol vehicles $(\mathrm{g} / \mathrm{s})$ :

$$
\begin{gathered}
\text { Emission }_{\text {diesel }}^{H C}=\left\{\begin{array}{lc}
1.13 \times 10^{-4} \times V S P+1.76 E-03, & V S P \leq-5 \\
-1.50 \times 10^{-4} \times V S P+4.50 E-04, & -5<V S P \leq-1 \\
1.50 \times 10^{-4} \times V S P+7.50 E-04, & -1<V S P \leq 7 \\
-1.00 \times 10^{-4} \times V S P+2.50 E-03, & V S P>7
\end{array}\right. \\
\text { Emission }_{\text {petrol }}^{H C}=\left\{\begin{array}{lc}
7.11 \times 10^{-6} \times V S P+1.01 E-04, & V S P \leq-3 \\
-4.67 \times 10^{-6} \times V S P+6.59 E-05, & -3<V S P \leq 3 \\
7.58 \times 10^{-6} \times V S P+2.92 E-05, & V S P>3
\end{array}\right.
\end{gathered}
$$

(3) Vehicle emissions estimation model of $\mathrm{NO}_{X}$ for diesel and petrol vehicles $(\mathrm{g} / \mathrm{s})$ :

$$
\begin{gathered}
\text { Emission }_{\text {diesel }}^{N O_{X}}=\left\{\begin{array}{lc}
-0.0045 \times V S P+0.0174, & V S P \leq-3 \\
0.0070 \times V S P+0.0519, & -3<V S P \leq-1 \\
-0.0046 \times V S P+0.0403, & -1<V S P \leq 4 \\
0.0065 \times V S P-0.0042, & V S P>4
\end{array}\right. \\
\text { Emission }_{\text {petrol }}^{N O_{X}}=\left\{\begin{array}{lc}
-2.19 \times 10^{-5} \times V S P+7.22 E-05, & V S P \leq-2 \\
-1.26 \times 10^{-5} \times V S P+9.08 E-05, & -2<V S P \leq 3 \\
3.22 \times 10^{-5} \times V S P-4.35 E-05, & V S P>3
\end{array}\right.
\end{gathered}
$$

(4) Vehicle emissions estimation model of $\mathrm{CO}_{2}$ for diesel and petrol vehicles $(\mathrm{g} / \mathrm{s})$ :

$$
\text { Emission }_{\text {diesel }} \mathrm{CO}_{2}=\left\{\begin{array}{cc}
0.2851 \times V S P+6.0962, & V S P \leq-5 \\
-0.4885 \times V S P+2.2280, & -5<V S P \leq 1 \\
0.6019 \times V S P+1.1376, & 1<V S P \leq 9 \\
0.1653 \times V S P+5.0668, & V S P>9
\end{array}\right.
$$




$$
\text { Emission }_{\text {petrol }}^{\mathrm{CO}_{2}}=\left\{\begin{array}{lc}
0.1178 \times V S P+3.4445, & V S P \leq-3 \\
-0.3327 \times V S P+2.0931, & -3<V S P \leq 2 \\
0.3749 \times V S P+0.6779, & 2<V S P \leq 10 \\
-0.1950 \times V S P+6.3766, & V S P>10
\end{array}\right.
$$

The estimation results of the polynomial regression method $[25,48]$ were also calculated to compare the performance of our method in vehicle emissions estimation. This method applies to linear, quadratic, and cubic terms of transient speed and acceleration in a multiple regression model, in order to estimate vehicle emission rates. It is widely used in VSP-based vehicle emission estimation. The equation of primary polynomial regression model is

$$
\ln \left(E R_{e}\right)= \begin{cases}\sum_{i=0}^{3} \sum_{j=0}^{3} L_{i, j}^{e} \times v^{i} \times a^{j} & \text { for } a \geq 0 \\ \sum_{i=0}^{3} \sum_{j=0}^{3} M_{i, j}^{e} \times v^{i} \times a^{j} & \text { for } a<0\end{cases}
$$

where $E R_{e}$ means the instantaneous emission rate of pollutant $e(\mathrm{~g} / \mathrm{s}) ; L_{i, j}^{e}$ represents the coefficient of pollutant $e$ at transient speed $v(\mathrm{~km} / \mathrm{h})$ and acceleration $a\left(\mathrm{~m} / \mathrm{s}^{2}\right)$, while $a \geq 0$; and $M_{i, j}^{e}$ represents the coefficient of pollutant $e$ at transient speed $v(\mathrm{~km} / \mathrm{h})$ and acceleration a $\left(\mathrm{m} / \mathrm{s}^{2}\right)$ while $a<0$.

Several measurements, including mean absolute error (MAE), mean absolute percentage error (MAPE), root mean squared error (RMSE), and $R$-squared $\left(R^{2}\right)$ were selected to compare the performance of both methods [49]. The equations of these measures are

$$
\begin{gathered}
M A E=\frac{\sum_{i=1}^{N}\left|\hat{y}_{i}-y_{i}\right|}{N} \\
M A P E=\frac{1}{N} \sum_{i=1}^{N}\left|\frac{\hat{y}_{i}-y_{i}}{y_{i}}\right| \\
R M S E=\sqrt{\frac{\sum_{i=1}^{N}\left(\hat{y}_{i}-y_{i}\right)^{2}}{N}}
\end{gathered}
$$

where $N$ means the sample size; $y_{i}$ and $\hat{y}_{i}$ are actual and estimated vehicle emissions, respectively.

Table 3 shows the values of these measures of effectiveness (MOEs) for both methods. From this table, we can clearly find that the proposed method performs better and the values of the MOEs are all less than those of the polynomial regression method. The proposed model can reduce MAPE, $R M S E$, and MAE by $52.5 \%, 55.0 \%$, and $54.4 \%$, respectively. The $R^{2}$ of the proposed model is also larger than the polynomial regression method (0.833 vs 0.714$)$.

Table 3. Measures of effectiveness (MOEs) of two different models.

\begin{tabular}{ccccc}
\hline \multirow{2}{*}{ Method } & \multicolumn{4}{c}{ Measures of Effectiveness (MOEs) } \\
\cline { 2 - 4 } & MAPE (\%) & RMSE $(\mathrm{g} / \mathbf{s})$ & MAE $(\mathrm{g} / \mathbf{s})$ & $\boldsymbol{R}^{\mathbf{2}}$ \\
\hline $\begin{array}{c}\text { Proposed method } \\
\text { Polynomial }\end{array}$ & 7.015 & 0.068 & 0.057 & 0.833 \\
regression method & 14.766 & 0.151 & 0.125 & 0.714 \\
\hline
\end{tabular}

In order to explore the variations of vehicle emissions at different locations of freeway toll plazas more clearly and directly, total vehicle emissions, including $\mathrm{CO}, \mathrm{HC}, \mathrm{NO}_{x}$, and $\mathrm{CO}_{2}$, were calculated and drawn in heat maps. The freeway tool plaza area was divided into three sections: upstream area, toll plaza area, and downstream area. The length of these three areas were all $80 \mathrm{~m}$. The results 
of the heat maps show that, for ETC lanes (Figure $5 \mathrm{a}, \mathrm{c}$ ), the toll plaza area and downstream area generated more emissions than the upstream area for petrol and diesel vehicles. This is probably due to the acceleration process after the vehicles pass the toll plaza area and tend to enter the freeway. This process may cause more fuel consumption, which leads to more emissions. For MTC lanes, as shown in Figure $5 b, d$, the maximum emission values all occurred around the toll plaza area. This is because vehicles will undergo several stop-and-go cycles during the payment process. In addition, in contrast with ETC lanes, the upstream area generated more emissions than the downstream area for MTC lanes. This may due to the congestion caused by merging and stop-and-go behavior of front vehicles. Therefore, vehicle emissions in MTC lanes increase due to the excessive delays and speed variation cycles for approaching traffic. When comparing emission characteristics between petrol and diesel vehicles, we can find that the vehicle emissions of petrol vehicles are lower than diesel vehicles at upstream and toll plaza areas. However, the emissions of petrol vehicles increase in downstream areas. This phenomenon may be caused by higher acceleration rates and the longer acceleration process of petrol vehicles.

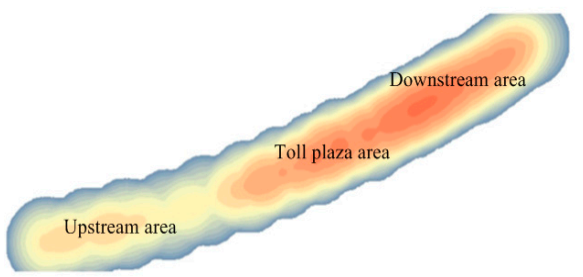

(a) petrol vehicles for ETC

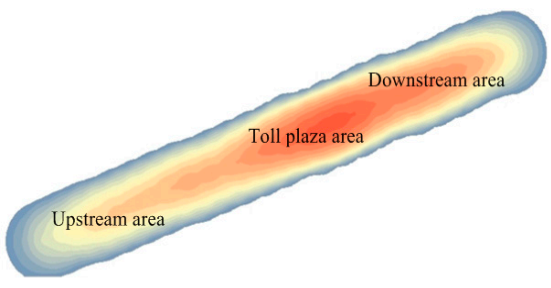

(c) diesel vehicles for ETC

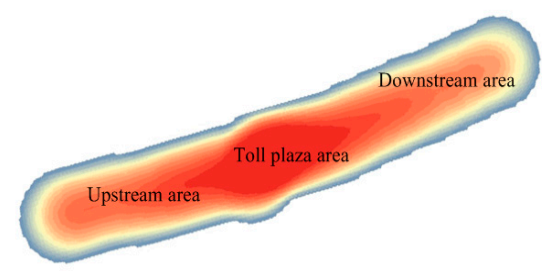

(b) petrol vehicles for MTC

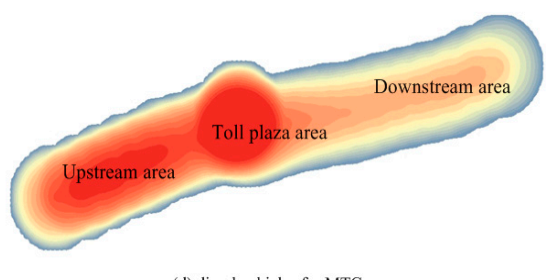

(d) diesel vehicles for MTC

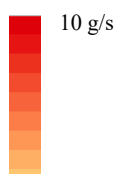

$0 \mathrm{~g} / \mathrm{s}$

Figure 5. Heat maps of emission variation at different locations of freeway toll plazas.

\section{Conclusions}

With the increasing concern about the environment and sustainable development, many studies have focused on the air pollution caused by transportation systems. A quantitative approach was proposed in this study to estimate the vehicle emissions at freeway toll plazas. The vehicle operation data (speed variation, acceleration, delay time) and vehicle emission data taken at ETC and MTC lanes for petrol and diesel vehicles were compared by Student's $t$-tests. After that, a model tree-based VSP regression was proposed to estimate the vehicle emissions of air pollutants at freeway toll plazas.

The data used in this study were obtained at two similar freeway toll plazas, with six MTC lanes and two ETC lanes. The $t$-tests indicate that the differences between ETC and MTC, and between petrol and diesel vehicles, are significant. This indicates that different types of toll collections and different vehicle fuel types have a significant influence on vehicle operations and emissions at freeway toll plazas.

After that, a polynomial regression method was applied to compare the proposed model trees' performance. Based on the MOEs, the proposed method performs better and the values of the MOEs are all less than those of the polynomial regression method. It can reduce MAPE, RMSE, and MAE by $52.5 \%, 55.0 \%$, and $54.4 \%$, respectively. The $R^{2}$ of the proposed model is also larger than the polynomial regression method ( 0.833 vs. 0.714$)$.

In order to explore the variations of vehicle emissions at different locations of freeway toll plazas more clearly and directly, heat maps were applied in this study. The results of the heat maps showed 
that, for ETC lanes, the toll plaza area and downstream area generated more emissions than the upstream area for petrol and diesel vehicles. For MTC lanes, the maximum emission values all occurred around the toll plaza area. This is because vehicles will suffer several stop-and-go cycles during the payment process. In contrast with ETC lanes, the upstream area generated more emissions than the downstream area for MTC lanes. This may due to the congestion caused by merging and stop-and-go behavior of front vehicles. When comparing emission characteristics between petrol and diesel vehicles, we can find that the vehicle emissions of petrol vehicles are lower than those of diesel vehicles at upstream and toll plaza areas. However, the emissions of petrol vehicles become higher in downstream areas. This phenomenon may be caused by higher acceleration rates and longer acceleration process of petrol vehicles.

With the proposed method, it is feasible to estimate the vehicle emissions at freeway toll plazas. The results also indicate that the application of ETC lanes can reduce air pollution at freeway toll plazas, which can give support to the development of ETC in China. We will try to obtain more samples from different sites in the future, in order to further improve and verify the performance of the model. In addition, the performance of the proposed model may be influenced by different road grades or different weather conditions. Further studies will be conducted to explore their impacts and improve the performance of the model. Agent-based traffic simulation and driving behavior models will also be applied in the future to further explore the potential causes of vehicle emission variations for ETC and MTC lanes at different locations.

Author Contributions: Conceptualization, Y.X. and C.W.; data curation, Y.X. and Y.Z.; formal analysis, Y.X. and C.W.; funding acquisition, Z.Y.; methodology, Y.X., C.W., and Z.S.; resources, Z.Y.; validation, Y.X.; writing —original draft, Y.X.; writing — review and editing, C.W. and Y.Z. All authors have read and agreed to the published version of the manuscript.

Funding: This study was founded by the Scientific Research Foundation of the Graduate School of Southeast University (No. YBJJ1633), the Fundamental Research Funds for the Central Universities, and the Scientific Research Program of the Graduate School of Jiangsu Province (No. KYLX16-0280).

Conflicts of Interest: The authors declare no conflict of interest

\section{Nomenclature}

The Nomenclature of variables in this paper are listed as follows:

$\begin{array}{ll}A & \text { The frontal area of the vehicle }\left(\mathrm{m}^{2}\right) \\ a & \text { The vehicle acceleration value }\left(\mathrm{m} / \mathrm{s}^{2}\right) \\ C_{d} & \text { The drag coefficient }(0.6) \\ \text { Emission }_{\text {diesel }}^{\mathrm{CO}} & \text { Emissions of } \mathrm{CO} \text { for diesel vehicles } \\ \text { Emission }_{\text {petrol }}^{\mathrm{CO}} & \text { Emissions of } \mathrm{CO} \text { for petrol vehicles } \\ \text { Emission }_{\text {diesel }}^{\mathrm{HC}} & \text { Emissions of } \mathrm{HC} \text { for diesel vehicles } \\ \text { Emission }_{\text {petrol }}^{\mathrm{HC}} & \text { Emissions of } \mathrm{HC} \text { for petrol vehicles } \\ \text { Emission }_{\text {diesel }}^{\mathrm{NO}} & \text { Emissions of } \mathrm{NO}_{\mathrm{X}} \text { for diesel vehicles } \\ \text { Emission }_{\text {petrol }}^{\mathrm{NO}} & \text { Emissions of } \mathrm{NO}_{\mathrm{X}} \text { for petrol vehicles } \\ \text { Emission }_{\text {diesel }}^{\mathrm{CO}} & \text { Emissions of } \mathrm{CO}_{2} \text { for diesel vehicles } \\ \text { Emission }{ }_{\text {petrol }}^{\mathrm{CO}} & \text { Emissions of } \mathrm{CO}_{2} \text { for petrol vehicles } \\ \text { ERe } & \text { The instantaneous emission rate of pollutant } e(\mathrm{~g} / \mathrm{s}) \\ F_{a} & \text { Acceleration resistance }(\mathrm{N}) \\ F_{f} & \text { Rolling resistance }(\mathrm{N}) \\ F_{t} & \text { The vehicle traction }(\mathrm{N}) \\ F_{w} & \text { Wind resistance }(\mathrm{N}) \\ G & \text { Gravity of the vehicle }(\mathrm{N}) \\ g & \text { The gravitational acceleration }\left(9.81 \mathrm{~m} / \mathrm{s}^{2}\right) \\ k & \text { A constant value }\end{array}$




$\begin{array}{ll}L_{i, j}^{e} & \begin{array}{l}\text { The coefficient of pollutant } e \text { at transient speed } v \\ (\mathrm{~km} / \mathrm{h}) \text { and acceleration } a\left(\mathrm{~m} / \mathrm{s}^{2}\right) \text { while } a \geq 0\end{array} \\ M_{i, j}^{e} & \begin{array}{l}\text { The coefficient of pollutant } e \text { at transient speed } v \\ (\mathrm{~km} / \mathrm{h}) \text { and acceleration a }\left(\mathrm{m} / \mathrm{s}^{2}\right) \text { while } a<0\end{array} \\ m & \text { The total vehicle mass }(\mathrm{kg}) \\ M A E & \text { Mean absolute error } \\ M A P E & \text { Mean absolute percentage error } \\ N & \text { The sample size } \\ p^{\prime} & \text { The predicted value passed up to the higher node } \\ p & \text { The predicted value passed to this node from the } \\ q & \text { lower node } \\ R M S E & \text { The value predicted by the model at this node } \\ S D R & \text { Root mean squared error } \\ S d & \text { The standard deviation reduction } \\ T & \text { The standard deviation } \\ T_{i} & \text { The example sets that reach the node } \\ v & \text { The sets that are generated by splitting the node } \\ v_{w} & \text { based on the selected attribute } \\ V S P_{\text {petrol }} & \text { The transient speed (m/s) } \\ V S P_{\text {diesel }} & \text { The headwind speed into the vehicle }(\mathrm{m} / \mathrm{s}) \\ V S P & \text { Vehicle-specific power for petrol vehicles } \\ y_{i} & \text { Vehicle-specific power for diesel vehicles } \\ \hat{y}_{i} & \text { Vehicle-specific power } \\ \alpha & \text { Actual vehicle emissions } \\ \varepsilon & \text { Estimated vehicle emissions } \\ \mu & \text { The road grade } \\ \rho_{a} & \text { The mass factor } \\ & \text { The rolling resistance coefficient }\end{array}$

\section{References}

1. Yao, X.; Hu, Q.; Zhang, L.; Evans, G.J.; Godri, K.J.; Ng, A.C. Is vehicular emission a significant contributor to ammonia in the urban atmosphere? Atmos. Environ. 2013, 80, 499-506. [CrossRef]

2. $\mathrm{Yu}, \mathrm{Q}$; $\mathrm{Li}, \mathrm{T}$. Evaluation of bus emissions generated near bus stops. Atmos. Environ. 2014, 85, 195-203. [CrossRef]

3. Wang, C.; Ye, Z.; Wang, W.; Jin, M. Traffic-related heavy metal contamination in urban areas and correlation with traffic activity in China. Transp. Res. Record 2016, 2571, 80-89. [CrossRef]

4. Alam, A.; Ghafghazi, G.; Hatzopoulou, M. Traffic emissions and air quality near roads in dense urban neighborhood: Using microscopic simulation for evaluating effects of vehicle fleet, travel demand, and road network changes. Transp. Res. Record 2014, 2427, 83-92. [CrossRef]

5. Mishra, D.; Goyal, P. Estimation of vehicular emissions using dynamic emission factors: A case study of Delhi, India. Atmos. Environ. 2014, 98, 1-7. [CrossRef]

6. Vedrenne, M.; Borge, R.; Lumbreras, J.; Rodriguez, M.E.; De la Paz, D.; Perez, J.; De Andres, J.M.; Quaassdorff, C. A comprehensive approach for the evaluation and comparison of emission inventories in Madrid. Atmos. Environ. 2016, 145, 29-44. [CrossRef]

7. Lumbreras, J.; Valdes, M.; Borge, R.; Rodriguez, M.E. Assessment of vehicle emissions projections in Madrid (Spain) from 2004 to 2012 considering several control strategies. Transp. Res. Pt. A Policy Pract. 2008, 42, 646-658. [CrossRef]

8. Ahn, K.; Rakha, H. The effects of route choice decisions on vehicle energy consumption and emissions. Transport. Res. Part D Transport. Environ. 2008, 13, 151-167. [CrossRef]

9. Bartin, B.; Mudigonda, S.; Ozbay, K. Impact of electronic toll collection on air pollution levels: Estimation using microscopic simulation model of large-scale transportation network. Transp. Res. Record 2007, 2011, 68-77. [CrossRef] 
10. He, J.; Qi, Z.; Hang, W.; King, M.; Zhao, C. Numerical evaluation of pollutant dispersion at a toll plaza based on system dynamics and computational fluid dynamics models. Transp. Res. Part C Emerg. Technol. 2011, 19, 510-520. [CrossRef]

11. He, J.; Qi, Z.; Zhao, C.; Bao, X. Simulations of pollutant dispersion at toll plazas using three-dimensional CFD models. Transport. Res. Part D Transport. Environ. 2009, 14, 557-566. [CrossRef]

12. Demir, E.; Bektas, T.; Laporte, G. A comparative analysis of several vehicle emission models for road freight transportation. Transport. Res. Part D Transport. Environ. 2011, 16, 347-357. [CrossRef]

13. Tseng, P.; Lin, D.; Chien, S. Investigating the impact of highway electronic toll collection to the external cost: A case study in Taiwan. Technol. Forecast. Soc. Chang. 2014, 86, 265-272. [CrossRef]

14. Lin, J.; Yu, D. Traffic-related air quality assessment for open road tolling highway facility. J. Environ. Manag. 2008, 88, 962-969. [CrossRef]

15. Coelho, M.C.; Farias, T.L.; Rouphail, N.M. Measuring and modeling emission effects for toll facilities. Transp. Res. Record 2005, 1941, 136-144. [CrossRef]

16. Cheng, Y.; Li, Y. Influences of traffic volumes and wind speeds on ambient ultrafine particle levels-Observations at a highway electronic toll collection (ETC) lane. Atmos. Environ. 2011, 45, 117-122. [CrossRef]

17. Saka, A.A.; Agboh, D.K. Assessment of operational benefits of electronic toll collection in Baltimore metropolitan area. In Proceedings of the 81st Annual Meeting of the Transportation Research Board, Washington, DC, USA, 13-17 January 2002.

18. Tong, H.; Hung, W.; Cheung, C. On-road motor vehicle emissions and fuel consumption in urban driving conditions. J. Air Waste Manag. Assoc. 2000, 50, 543-554. [CrossRef]

19. St. Denis, M.J.; Cicero-Fernandez, P.; Winer, A.M.; Butler, J.W.; Jesion, G. Effects of in-use driving conditions and vehicle/engine operating parameters on "Off-Cycle" events: Comparison with federal test procedure conditions. J. Air Waste Manag. Assoc. 1994, 44, 31-38.

20. Joumard, R.; Jost, P.; Hickman, J. Influence of Instantaneous Speed and Acceleration on Hot Passenger Car Emissions and Fuel Consumption; (No. 950928); Society of Automotive Engineers: Warren dale, PA, USA, 1995.

21. Rapone, M.; Ragione, L.D.; D'Aniello, F.; Luzar, V. Experimental Evaluation of Fuel Consumption and Emissions in Congested Urban Traffic; (No. 952401); Society of Automotive Engineers: Warrendale, PA, USA, 1995.

22. Song, G.; Yu, L.; Zhang, X. Emission Analysis at a Toll Station in Beijing using PEMS Measurements. In Proceedings of the 87th Annual Meeting of the Transportation Research Board, Washington, DC, USA, 13-17 January 2008.

23. Mahesh, S.; Ramadurai, G.; Nagendra, S.S. On-board measurement of emissions from freight trucks in urban arterials: Effect of operating conditions, emission standards, and truck size. Atmos. Environ. 2019, 212, 75-82. [CrossRef]

24. Wang, C.; Sun, Z.; Ye, Z. On-Road Bus Emission Comparison for Diverse Locations and Fuel Types in Real-World Operation Conditions. Sustainability 2020, 12, 1798. [CrossRef]

25. Rakha, H.; Ahn, K.; Trani, A. Development of VT-micro model for estimating hot stabilized light duty vehicle and truck emissions. Transport. Res. Part D Transport. Environ. 2004, 9, 49-74. [CrossRef]

26. Ruths, M.; Von Bismarck-Osten, C.; Weber, S. Measuring and modelling the local-scale spatio-temporal variation of urban particle number size distributions and black carbon. Atmos. Environ. 2014, 96, 37-49. [CrossRef]

27. Xu, C.; Zhao, J.; Liu, P. A geographically weighted regression approach to investigate the effects of traffic conditions and road characteristics on air pollutant emissions. J. Clean Prod. 2019, 239, 118084. [CrossRef]

28. Pan, Y.; Chen, S.; Qiao, F.; Ukkusuri, S.V.; Tang, K. Estimation of real-driving emissions for buses fueled with liquefied natural gas based on gradient boosted regression trees. Sci. Total Environ. 2019, 660, 741-750. [CrossRef]

29. Wang, C.; Ye, Z.; Yu, Y.; Gong, W. Estimation of bus emission models for different fuel types of buses under real conditions. Sci. Total Environ. 2018, 640, 965-972. [CrossRef]

30. Azeez, O.S.; Pradhan, B.; Shafri, H.Z.M. Vehicular CO Emission Prediction Using Support Vector Regression Model and GIS. Sustainability 2018, 10, 3434. [CrossRef]

31. Weng, J.; Wang, R.; Wang, M.; Rong, J. Fuel consumption and vehicle emission models for evaluating environmental impacts of the ETC system. Sustainability 2015, 7, 8934-8949. [CrossRef] 
32. Kheawubon, C.; Usapein, P.; Khedari, J. Impact of Electronic Toll Collection System on Energy Saving and $\mathrm{CO}_{2}$ emission: A Case Study of Passenger Cars in Thailand. Int. J. Renew. Energy Res. 2018, 8, 1840-1848.

33. Bari, C.S.; Navandar, Y.V.; Dhamaniya, A. Vehicular Emission Modeling at Toll Plaza Using Performance Box Data. J. Hazard. Toxic Radioact. Waste 2020, 24, 05020003. [CrossRef]

34. Yu, Q.; Li, T.; Li, H. Improving urban bus emission and fuel consumption modeling by incorporating passenger load factor for real world driving. Appl. Energy 2016, 161, 101-111. [CrossRef]

35. Song, G.; Yu, L. Characteristics of low-speed VSP distribution on urban restricted access roadways in Beijing. Transp. Res. Record 2011, 2233, 90-98. [CrossRef]

36. Breiman, L.; Friedman, J.H.; Olshen, R.A.; Stone, C.J. Classification and Regression Trees; Wadsworth International: Belmont, CA, USA, 1984.

37. Zhang, R.; Jing, J.; Tao, J.; Hsu, S.C.; Wang, G.; Gao, J.; Lee, C.S.L.; Zhu, L.; Chen, Z.; Zhao, Y.; et al. Chemical characterization and source apportionment of PM2.5 in Beijing: Seasonal perspective. Atmos. Chem. Phys. 2013, 13, 7053-7074. [CrossRef]

38. Shahinian, V.D. On-Vehicle Diesel Emission Analyzer: SEMTECH-DS User Manual: Revision 1.14; Elsevier: Alpharetta, GA, USA, 2007.

39. Jimenez-Palacios, J.L. Understanding and quantifying motor vehicle emissions with vehicle specific power and TILDAS remote sensing. Ph.D. Thesis, Massachusetts Institute of Technology, Cambridge, MA, USA, 1998.

40. Bapat, A.; Gao, H.O. Diesel particulate matter number emissions: Evaluation of existing modal emission modeling approaches. J. Transp. Eng. 2010, 136, 93-101. [CrossRef]

41. Rakha, H.; Lucic, I.; Demarchi, S.H.; Setti, J.R.; Aerde, M.V. Vehicle dynamics model for predicting maximum truck acceleration levels. J. Transp. Eng. 2001, 127, 418-425. [CrossRef]

42. Quinlan, J.R. Learning with Continuous Classes. In Proceedings of the 5th Australian Joint Conference on Artificial Intelligence, Singapore, 16-18 November 1992; pp. 343-348.

43. Etemad-Shahidi, A.; Mahjoobi, J. Comparison between M5' model trees and neural networks for prediction of significant wave height in Lake Superior. Ocean Eng. 2009, 36, 1175-1181. [CrossRef]

44. Harrington, P. Machine Learning in Action; Manning Publications: Shelter Island, NY, USA, 2012; ISBN 1617290181.

45. Wang, Y.; Witten, I.H. Induction of Model Trees for Predicting Continuous Lasses. Available online: https://researchcommons.waikato.ac.nz/handle/10289/1183 (accessed on 17 August 2020).

46. Borge, R.; De Miguel, I.; De la Paz, D.; Lumbreras, J.; Perez, J.; Rodriguez, E. Comparison of road traffic emission models in Madrid (Spain). Atmos. Environ. 2012, 62, 461-471. [CrossRef]

47. Witten, I.; Frank, E.; Mark, A. Hall Data Mining: Practical Machine Learning; Elsevier: Amsterdam, The Netherlands, 2011; ISBN 9780123748560.

48. Ahn, K.; Rakha, H.; Trani, A.; Van Aerde, M. Estimating vehicle fuel consumption and emissions based on instantaneous speed and acceleration levels. J. Transp. Eng. 2002, 128, 182-190. [CrossRef]

49. Wang, C.; Ye, Z. Traffic flow forecasting based on a hybrid model. J. Intell. Transport. Syst. 2016, 20, 428-437. [CrossRef]

Publisher's Note: MDPI stays neutral with regard to jurisdictional claims in published maps and institutional affiliations.

(C) 2020 by the authors. Licensee MDPI, Basel, Switzerland. This article is an open access article distributed under the terms and conditions of the Creative Commons Attribution (CC BY) license (http://creativecommons.org/licenses/by/4.0/). 